\title{
In Defense of Materialism: The Haitian Zonbi Vs. the Philosophical Zombie
}

\author{
Paul CMocombe \\ The Mocombeian Foundation, Inc, West Virginia State University, USA
}

\begin{abstract}
This work contrasts the concept of the philosophical zombie, p-zombie, with its conception as found in Haitian ontology, zonbi, to understand the material nature of consciousness constitution in the multiverse. Whereas the former is utilized to substantiate the mind-body dualism; the latter as I see it negates the dualism to offer a complete materialist understanding of consciousness constitution, which eliminates the mind-body dualism.
\end{abstract}

\section{Keywords}

Haitian epistemology, Structurationism, Praxis, Panpsychism, Social class language game, Phenomenological Structuralism, ORCH-OR theory, Philosophical zombie, The hard problem, The binding problem

\section{Introduction}

This work contrasts the concept of the philosophical zombie, p-zombie, with its conception as found in Haitian ontology, zonbi, to understand the material nature of consciousness constitution. Whereas the former is utilized to substantiate the mind-body dualism; the latter as I see it negates the dualism to offer a complete materialist understanding of consciousness constitution, which eliminates the mind-body dualist position.

\section{Background of the Problem}

Consciousness here refers to subjective awareness of phenomenal experiences (ideology, language, self, feelings, choice, control of voluntary behavior, thoughts, etc.) of internal and external worlds. The academic literature "describes three possibilities regarding the origin and place of consciousness in the universe: (A) As an emergent property of complex brain neuronal computation, (B) As spiritual quality of the universe, distinct from purely physical actions, and (C) As composed of discrete 'proto-conscious' events acting in accordance with physical laws not yet fully understood" [1]. The latter position, (C), represents the ORCH-OR ("orchestrated objective reduction") theory of Stuart Hameroff and Roger Penrose [1], which includes aspects of $(A)$ and $(B)$, and posits that "consciousness consists of discrete moments, each an 'orchestrated' quantum-computational process terminated by... an action [,objective reduction or $\mathrm{OR}$,] rooted in quantum aspects of the fine structure of space-time geometry, this being coupled to brain neuronal processes via microtubules" (pg. 70). In this view, the understanding is that a proto-conscious experience existed in the early universe, panpsy- chism, and as a result of emergent structures of the brain it (proto-conscious experience, psychion) became embodied and evolved as a result of quantum neuronal computations of "brains". The philosophical zombie, p-zombie, is a thought experiment in the philosophy of mind conceived by mind-body dualists such as David Chalmers to refute (A), which offers a complete materialist account of consciousness, in favor of (B).

The hard problem of consciousness, introduced in the discourse of consciousness constitution by David Chalmers [2], seeks to understand how and why sentient beings have phenomenal experiences or felt states, qualia, like pain, excitement, heat, etc. This latter problem is tied to the binding problem, which seeks to understand what accounts for the unity of experience. Chalmers introduces the $p$-zombie thought experiment to refute a complete materialist account of consciousness in favor of a mind-body dualism. According to the p-zombie thought experiment, if zombies exist they would be indistinguishable from normal human beings with the exception that they would not have conscious experience, qualia, or sentience. For Chalmers, and other dualists, this is a contradiction. If zombies are indistinguishable from normal human beings, it holds to

*Corresponding author: Paul C Mocombe, The Mocombeian Foundation, Inc, West Virginia State University, USA

Accepted: January 16, 2020

Published online: January 18, 2020

Citation: Mocombe PC (2020) In Defense of Materialism: The Haitian Zonbi Vs. the Philosophical Zombie. Insights Anthropol 4(1):233-236 
reason that they would possess conscious experience, which substantiates his mind-body position. In this article, I utilize the notion of zombies as found in Haitian ontology and practice, zonbi, to refute the dualist position in favor of a complete materialist account of consciousness constitution as found in (C). Thus the understanding here is that what accounts for the unity of experience is the psychion, subatomic particle, of an emergent psychonic/panpsychic subatomic field of the multiverse that has phenomenal properties, which gets embodied as neuronal particles of the aggregated brain, which experiences a material resource framework as an "I" whose phenomenal properties following matter disaggregation either returns back to the field or collapses in other worlds where the same matter exists. This Mocombeian [3] materialization parallels the concept and practice of nanm (soul/consciousness) and zonbi found in Haitian metaphysics.

\section{Theory and Method}

Paul C. Mocombe's [3,4] structurationist sociology, phenomenological structuralism, which attempts to resolve the structure/agency problematic of the social sciences, builds on the ORCH-OR theory and panpsychism of Hameroff and Penrose, while holding on to the multiverse hypothesis of quantum mechanics and Haitian ontology/ epistemology, which the authors reject, the former, because it is not "a more down-to-earth viewpoint" [1]. For Mocombe [3], quantum superposition, entanglement, and evidence in Haitian Vodou of spirit possession, which represent ancestors from a parallel world, Vilokan, of the earth's of which we ought to pattern our behaviors and structures, are grounding proofs for the acceptance of the multiple worlds hypothesis of quantum mechanics within an M-theory interpretation of the constitution of the multiverse [3,5-8]. Within the latter hypothesis, the understanding is that "each possibility in a superposition evolves to form its own universe, resulting in an infinite multitude of coexisting 'parallel' worlds. The stream of consciousness of the observer is supposed somehow to 'split', so that there is one in each of the worlds-at least in those worlds for which the observer remains alive and conscious. Each instance of the observer's consciousness experiences a separate independent world, and is not directly aware of any of the other worlds" [1]. It is within this multiple worlds, which are materially real, hypothesis that Mocombe constitutes the notion of consciousness in the universe according to his theory of phenomenological structuralism. For Mocombe [3], the material world is real and objective, and the informational content of consciousness is epiphenomenal content recycled/entangled/ superimposed throughout the multiverse after matter aggregation and experience. Consciousness is an emergent fifth force of nature, a quantum material substance/energy, psychion, the phenomenal property of which is recycled/entangled/superimposed throughout the multiverse and becomes embodied via the microtubules of brains. It is manifested in simultaneous, entangled, superimposed, and interconnecting material resource frameworks as embodied praxis or practical consciousness, which in-turn becomes the phenomenal properties of material (subatomic particle energy, psychion) consciousness that is recycled/ entangled/superimposed throughout the multiverses via (self-aware or not) practical activity and the phenomenal properties of subatomic particles of a psychonic/panpsychic field, which goes on to produce aggregated matter with consciousness.

In other words, Paul C. Mocombe's [3] structurationist theory of phenomenological structuralism, in keeping with the logic of structurationist sociology, assumes practical activity and consciousness, i.e., practical consciousness, to be the basis for understanding human behavior and consciousness in the world. For Mocombe, this consciousness is neither an emergent illusion of the brain or one that comes from a simulation of species-Beings with "higher consciousness" than our human form, nor a God, which animates our species-being with its essence that is our human soul/consciousness. The aforementioned positions, a simulation/virtual reality, emergent property of the mechanical brain, or the essence of God, presupposes the existence of consciousness as fundamental to the multiverse prior to its embodiment as the "I," the Cartesian thinking subject, of the human actor. In Mocombe's theory of phenomenological structuralism, consciousness, like the other forces of the multiverse, is presupposed as a proto-evolutionary force with a subatomic field whose particles become embodied via microtubules of brains. In other words, consciousness is an emergent fifth force of nature, a psychion of a psychonic/panpsychic subatomic field, which evolves via experience of the macro-world as embodied aggregated neuronal energy, in microtubules of brains, recycled/entangled/superimposed throughout the multiverses. Hence, it is not solely an emergent property of the mechanical brain; a simulation (virtual reality) wherein sentient beings with consciousness are the pawns in the conscious scenarios of a species-being with higher-consciousness; nor is it a product of a God, in the Christian sense, animating it in its consciousness. Even if the latter two (which makes up the virtual reality hypothesis in some physic circles) were the case, neither would deny the fact that we are able to know the laws of the "material" simulation by which we become conscious or have consciousness, which appears to be fundamental prior to time and space of the macro-worlds. I disagree with this virtual reality hypothesis of the multiverse. For me, the multiverse is real and objective, and consciousness is not fundamental to it. Instead, consciousness is, like time and space, an emergent property of the macro-world, which evolves as a force of nature akin to the evolution of gravity. In other words, it becomes an emergent force of nature, which is recycled/ entangled/superimposed throughout the multiverse, after the constitution of the macro-world: Consciousness is the product of neuronal energies, psychion, of a psychonic/ panpsychic subatomic field, the phenomenal properties of which aggregate as matter, via the other forces of nature, and manifests itself in the multiverse as embodied practical activity, i.e., practical consciousness, of species, whose consciousness, once disaggregated as matter in one universe, either collapses unto other versions of itself that exists in other multiverses, or is recycled into the psychonic/panpsychic subatomic field as particles with phenome- 
nal properties, i.e., qualia. So the phenomenal properties, qualia, of subatomic particles is the binding elements that give unity to consciousness in the brains of sentient beings, which experience this unity as neuronal phenomenal experience of an " $\mathrm{l}$ " in order to experience and exist in a material resource framework.

\section{Discussion and Conclusion}

Mocombe [9] builds on Haitian ontology's notion of the nanm and zonbi to understand the constitution of consciousness as a proto-material substance of the multiverse whose phenomenal properties, once disaggregated as aggregated matter, constitutes a psychonic/panpsychic field the psychion of which gives unity to our experiences and felt experiences once embodied. Hence like Haitian/Vilokan Idealism which posits that the nanm, which provides unity to our experiences is a material thing, a Cartesian I composed of three distinct entities (sometimes more as Haitian metaphysics suggests that a fourth entity, Iwa met tet, may constitute the nanm of serviteurs in order to guide them in their decision-making) that are also tied to the natural world and can be manipulated in life as well as death, I, also, view consciousness as an emergent proto-material substance, which becomes reified and embodied as the phenomenal properties of subatomic particles following the constitution of the macro-world.

As the late ATI-oungan of the religion of Haitian Vodou, Max Beauvoir [5], highlights about the nanm and zombification, in Haitian ontology, the human being is a sentient being, which is constituted as three distinct material entities, the physical body, the gwo bon anj (sé médo), and the ti bon anj (sé lido). The latter two constitute our nanm (soul), and the physical body is aggregated matter that eventually dies and rots. It is animated by the energy force of Bon-dye or the universe, the gwo bon anj, which is not active in influencing personality or the choices that the human subject makes in life. Instead, it is simply the spark of life or the energy force that keeps the body living or activated. In other words, metaphorically speaking, imagine the body as an electrical cord, Bon-dye as the socket, and the spark of energy from the socket that animates the appliance as the gwo bon anj.

The animated body, the physical body and the gwo bon anj, gives rise to consciousness and the personality through the ti bon anj. The most important part of the body is the head, which is the seat of consciousness and the space where sight, hearing, smell, and taste all reside. The five senses of the head, and the brain's reflection on what is smelled, heard, seen, tasted, and touched gives rise to the ti bon anj, which is consciousness, intellect, reflection, memory, will, and the personality. That is to say, it is the ti bon anj that houses the ego, self, personality, and ethics of the person from experiences in life. So the gwo bon anj animates the physical body, which gives rise to the ti bon anj, i.e., the individual ego or I of a human subject as they experience being in the world with others.

The three aforementioned distinct (materialist) entities constitute the average individual and can be separated at various points throughout their life cycle and at the time of death. People who are called to work with Iwa yo (spirits and concepts in Haitian Vodou) also have a fourth entity, personal lwa, mét tét, who permanently resides within their head, i.e., a sort of split personality that guides the individual in making important and daily decisions. For the average individual, at the time of death the physical body dies and rots, the ti bon anj, the ego, personality, etc., returns to Ginen (Africa), Vilokan, and the gwo bon anj lingers around seeking to animate a new body. Serviteurs, oungan yo, Manbo yo, and Bokor yo, can work to bring the $t i$ bon anj of elders back across the waters from Africa so that they can be an active and honored ancestor. This latter process of ancestor retrieval is usually done a day and a year after the death of the person, and requires an animal sacrifice, i.e., the taking of a life to feed Iwa yo in order to retrieve the deceased ancestor from Ginen. Upon retrieval, the ti bon anj of the ancestor is kept in a govi, a small clay bottle. Bokors, sorcerers, who are members of secret societies in Vodou, and stand apart from oungan yo (priests) and Manbo yo (priestesses) as sorcerers who serve Petwo I wa yo, can also capture the lingering ti bon anj to do spiritual work aimed at healing, ascertaining money, love relationships, work, political power, i.e., pwen, or other desires. This latter act is one form of zombification wherein the ti bon anj of a deceased person is captured in a bottle, govi, and directed to serve either the Bokor or an individual seeking wealth, love, political power, or to do harm to another person, etc.

Aside from separation in death, separation can also take place during a person's life cycle. During a person's life cycle, the gwo bon anj can be displaced by a Iwa during possession or a Bokor for zombification. The Iwa utilizes the animated body (the person possessed is called a chawl or horse for the Iwa) to experience the world, heal, protect, etc. The ti bon anj can be displaced during a person's life cycle by a Bokor for the mitigation of punishment through zombification. This latter action is essentially the death penalty in Vodou when individuals morally violate nature, communal life, or an individual. Bokor yo are called upon by oungan yo and manbo yo to punish the transgressor through the removal of their ti bon anj from their bodies. During this process, the ego and personality, ti bon anj, which is viewed as a material thing, is removed, and the person is left with the material body and the gwo bon anj. The purpose of this act is to render the transgressor without the desire and drive (will) to commit any further acts, which arose from their ti bon anj. The person is not killed, but the desire and passion that caused them to commit the initial transgression that they committed is removed. Hence the person is left alive as a mindless zombie, i.e., zonbi. Essentially, whereas oungan yo, manbo yo, and gangan/dokté fey are the readers, judges, and healers, Bokor yo are the sorcerers and police force of the village. They are practitioners of black magic, and are visited by people seeking to do harm to someone, wealth, power, luck, revenge, etc. There are three other, external, cosmic force and lwa yo that impact the individual. They are the zetwal, i.e., the star of a person, which determines their fate; the Iwa rasin, or Iwa eritaj, the spirit of the ancestors "who enter the path of the unconscious to talk to 
him or her in dreams, to warn of danger, and to intervene at the many levels of his [or her] life"; and the wonsiyon, "these are a series of spirits that accompany the Iwa mét tét and modify somewhat the amplitude and the frequencies of its vibration or presence" [5].

Like Haitian ontology, highlighted by Max Beauvoir, I am a materialist, and view consciousness in similar material terms. For me, all aggregated matter in our dispensation of spacetime is composed of subatomic particle energies. Thus, to understand the constitution and origins of human practical consciousness one must begin with not only the actions (phenomenal properties, i.e., qualia) associated with these particles, but their essence or intrinsic nature, which is their inner conscious life (i.e., panpsychism), prior to understanding the sociocultural factors, which emerge as a result of matter aggregation and being-in-the-world.

So for me the multiverse is objective and real. There is no God in the multiverse (even if there was one, who created us as part of a simulation (virtual world) that is the multiverse, it would not matter or prevent us from understanding the rules and laws explaining the emergence and role of consciousness in the simulation), just consciousness, emanating from a psychonic or pan-psychic subatomic field, becoming and being in simultaneously existing present/past/future layered worlds, which are entangled and superimposed. The initial superverse, which created the multiverse is a product of quantum fluctuation of dark matter and energy, which funneled or exploded to create multiverses via the first four forces of nature, with consciousness being a later (evolutionary/emergent) force that emerged following species formation (matter aggremultiverses each interconnected via subatomic particles, which aggregated, via the initial four forces of nature, to form macro-worlds. Over time sentient beings experiencing these objective worlds emerged, and the phenomenal properties of their subatomic particles were/are recycled upon matter disaggregation to constitute a psychonic/ panpsychic field of the superverse, which would make consciousness an emergent (evolutionary) fifth force of nature endowing future sentient beings with consciousness, a fifth (evolutionary) force of nature. This consciousness is a neuronal energy field, which is not destroyed when matter is disaggregated; instead, it is either recycled into the psychonic/panpsychic subatomic field of the superverse, or entangled and superimposed into its counterparts where the disaggregated matter still exists in its aggregated forms in the multiverse. In the human ethos of the macro-world, the psychonic/pan-psychic subatomic field that is consciousness becomes God, which is associated with attributes that we embody or must embody in order to reproduce our being in material resource frameworks.

Generally speaking, consciousnesses, actions (practical gation) and death. That is, the superverse creates layered

consciousness), learning, and development within Mocombe's phenomenological structural ontology are the product of the embodiment of the phenomenal properties of recycled/entangled/superimposed subatomic neuronal energies/chemicals, psychion, of the multiverse objectified in the space-time of multiverses via the aggregated body and the microtubules of the brain. Once objectified and embodied the phenomenal properties of the neuronal energies/chemicals encounter the space-time of physical worlds via a transcendental subject of consciousnesses (the aggregation of a universal-self superimposed and entangled across the multiple worlds of the multiverse) and the drives and sensibilities of the aggregated body and brain in reified structures of signification, language, ideology, ideological apparatuses, and communicative discourse defined and determined by other beings that control the resources (economics), and modes of distributing them, of a material world required for physical survival in space-time. So in my view, contrary to Daniel Dennett, this transcendental subject of consciousnesses is not an emergent illusion of the brain. It (the transcendental subject of consciousnesses) is, following the constitution of macro-worlds throughout the multiverse, an emergent material substance superimposed/entangled/recycled via a psychonic/panpsychic subatomic field.

Future research must continue to find evidence for the superverse, multiverse, and the subatomic particle, psychion, and its field, which is consciousness.

\section{References}

1. Hameroff Stuart, Roger Penrose (2014) Consciousness in the Universe: A review of the 'Orch OR' theory. Physics of Life Reviews 11: 39-78.

2. David Chalmers (1995) Facing up to the problem of consciousness. Journal of Consciousness Studies 2: 200-219.

3. Paul C Mocombe (2019) The theory of phenomenological structuralism. Cambridge Scholars Publishing, Newcastle upon Tyne, UK.

4. Paul C Mocombe (2016) The vodou ethic and the spirit of communism: The practical consciousness of the African people of Haiti. University Press of America, Maryland.

5. Beauvoir M (2006) Herbs and energy: The holistic medical system of the Haitian people. In: Bellegarde-Smith P, Michel C, Haitian vodou: Spirit, myth, \& reality. Indiana University Press, Bloomington, 112-133.

6. Frankish Keith (2016) Why panpsychism fails to solve the mystery of consciousness. Aeon.

7. Price Huw, Ken Wharton (2016) Taming the quantum spooks. Aeon.

8. Frank Adam (2017) Minding matter. Aeon.

9. Mocombe Paul C (2019) Haitian epistemology. Cambridge Scholars Publishing, Newcastle upon Tyne, UK.

DOI: $10.36959 / 763 / 506$

Copyright: (c) 2020 Mocombe PC. This is an open-access article distributed under the terms of the Creative Commons Attribution License, which permits unrestricted use, distribution, and reproduction in any medium, provided the original author and source are credited.
SCHOLARS.DIRECT 